\title{
ОТ СОЦИОЛОГИИ К ОЦЕНКЕ
}

\section{FROM SOCIOLOGY TO EVALUATION}

\author{
ОЛЬГА ФРОЛОВА
}

\begin{abstract}
AвSTRACт. The article deals with figurative meanings of nominations of the social hierarchy relating to the upper, middle and lower strata of Russian society of the 18th and 19th centuries, and their reflection in the explanatory dictionary of the beginning of the 21st century. The use of adjectives, formed from personal nouns in the Russian National Corpus in the period 2000-2017, is analyzed.
\end{abstract}

Keywords: social stratification, social stratum, figurative meaning, metaphor, evaluation, ambivalence, connotation, Russian national corpus, democratization, image perception

Ольга Фролова, Московский государственный университет, Москва - Россия, olga_frolova@list.ru

ORCID ID: 0000-0002-7667-236X

Изучению процессов метафоризации в языке посвящены различные работы [см. Арутюнова 1978; Арутюнова 1990; Балашова 2014; Баранов 2014; Лакофф, Джонсон 2004; Телия 1988]. Метафорические значения формируются, в частности, у номинаций социальных страт и статусов в семантическом поле социальной стратификации. Собственно представление о слоях общества также является языковой метафорой и включено в картину мира [Сушкова-Ирина 2010]. Социальный аспект метафоризации на материале русского языка затрагивается в монографии Любови Викторовны Балашовой: среди различных и многообразных социальных отношений исследователь отмечает родственные, социальные - межличностные, внутригосударственные, межгосударственные, а также семантическое поле имущественных, товарно-денежных отношений и профессиональной деятельности человека. Метафоризация в сфере политики как важной сферы жизни общества также на русском материале описывается в монографии Анатолия Николаевича Баранова [Баранов 2014].

Мы хотим сосредоточиться на переносных значениях номинаций социальных статусов. Оценочные значения у слов, называющих разные группы общества, формируются в различные исторические эпохи, что отражено в лексикографических источниках. Например, Словарь Акаде- 
мии Российской (далее - САР) так описывает семантику прилагательного подлыи: “1) говорится о роде низкого происхождения, худородный... 2) Нечестно поступающий, заслуживающий презрение" [CAP 1809, IV: 1290], а Большой толковый словарь русского языка (далее - БТС) уже описывает значения прилагательного иначе:

1. Низкий, бесчестный. [...] || Свойственный низкому, бесчестному человеку... | | Выражающий низость, бесчестность; исполненный подлости. [...] 2. Разг. Очень плохой, скверный. [...] 3. Устар. Принадлежащий по рождению к низшему, податному сословию, неродовитый. § При Петре I люди, жившие наймом и чёрной работой, были отнесены к третьему классу подлых людей. [...] | | Свойственный людям такого происхождения. Подлые слово. Подлый язык. [...] [БТС 2002: 870].

Как видим, словарь начала XXI в. актуальное для XVIII в. значение отмечает как устаревшее, оценочные же значения выдвигаются на первый план. В том же Словаре Академии Российской семантика личного существительного подлец уже никак не связана с социальным аспектом и представлена исключительно как оценочная: “человек, поступками своими презрение заслуживающий" [CAP 1822, IV: 1286]. Лексикографические источники показывают, что деактуализация прямого номинативного значения стимулирует возникновение переносного.

Мы намереваемся проанализировать образование переносных значений у слова, называющего класс, а также номинаций человека, охарактеризованного на основании принадлежности к социальной группе: сословие, аристократ, обыватель, плебей, чернь. Выбранные нами слова отражают не всю систему социальной стратификации, а фрагменты ее верхнего, среднего и нижнего уровней. Мы рассматриваем функционирование интересующих нас единиц в постсоветский период, а точнее - в 2000-2017 гг. Для достижения поставленной цели нам нужно обратиться к толковым словарям; выбрать лексическую единицу, отражающую формирование коннотаций и характеризующего значения; показать закономерности в сочетаемости на материале Национального корпуса русского языка (далее НКРЯ), выявить появление коннотаций, не отраженных словарями.

\section{Сословие}

Обращаясь к энциклопедическому словарю, изданному еще в эпоху Российской империи, получаем, что

термином „сословие” обозначают отдельную группу подданных, своим юридическим положением каким-либо определенным образом отличающихся от остального населения, причем отличия эти передаются по наследству. В нашем законодательстве этому понятию соответствует термин „состояние” изредка, впрочем, в законе и в этом смысле тоже употребляется термин „сословие” [Лазаревский 1900]. 
Николай Иванович Лазаревский пишет о четырех сословиях, установившихся в Российской Империи после указа Екатерины II: дворянах, духовенстве, городских обывателях и сельских обывателях [Лазаревский 1900].

Современный Большой толковый словаръ объясняет семантику существительного сословие так:

1. Социальная группа с закреплёнными законом наследственными правами и обязанностями (окончательно сложившаяся на основе классового деления феодального общества). Привилегированные сословия (дворянство, духовенство). Податные сословия (крестьянство, мещанство). Духовное сословие. Дворянское сословие. Третье сословие. (во Франиии до революиии 1789 г.: непривилегированное податное население, крестьяне и горожане). 2. кого или какое. Ист. Широкая группа лиц, объединённая профессиональными интересами; корпорация. Чиновничье сословие. Сословие присяжных поверенных. Сословие медиков. 3. Шутл. Группа, разряд лиц, объединённых по какому-л. частному признаку. Шофёрское сословие. Женское, дамское с (о женщинах) [БТС 2002: 1240].

Словарь не дает помету устаревщее при первом значении. Второе и третье значения близки, отличаются же выбранным признаком, на основании которого люди объединяются в группу, и коннотацией. В третьем значении такой признак выбран произвольно. Так, словарь отражает, с одной стороны, иерархическое устройство общества в первом значении, а с другой стороны - в третьем, переносном, значении тенденции демократизации, размывающие строгую феодальную вертикальную организацию социума.

Употребление в подкорпусе 2000-2017 существительного сословие показывает, что данное слово может сохранять шутливость, отмеченную словарем, или лишаться ее (примеры 1, 2).

(1) Доктором физ.-мат. Нау стал самостоятельно, но не включал себя ни в сословие математиков, ни в сословие физиков (Геннадий Горелик, Науки естественные и искусственные, „Знание - сила”, 2010) [НКРЯ];

(2) Здесь вотчина еще одного воровского сословия - барсеточников (Дмитрий Виноградов. Глазами мента, „Русский репортер” , № 14 (93), 16-23 апреля 2009) [НКРЯ].

Сочетаемость в текстах 2000-2017 гг. подтверждает произвольность выбора признака, на основании которого люди объединены в ту или иную группу. При этом употребление как бы балансирует между вторым или третьим значениями, описанными словарем. Можно выделить две модели: а) прилагательное, образованное от названия социальной группы или страты, характеристик группы, а также от номинации сфе- 
ры занятости + существительное сословие; б) слово сословие + зависимое личное существительное, называющие социальную группу в форме родительного падежа множественного числа. Первая модель употребительнее: сословие бомжовое, деловое, интелигентское, креативное, надстроечное, образованное, предпринимательское. Вторая модель представлена скупее: сословие лавочников.

\section{Аристократ, аристократический}

Согласно БТС, аристократ - „1. Представитель аристократии (1 зн.). 2. Разг. О человеке изысканном, утонченном, но высокомерном..." [БТС 2002: 46]. Отрицательная оценка выражается в прилагательном высокомерный, включенном в толкование. Словарь не дает никаких стилистических помет. Существительное аристократия, к которому словарь отсылает в объяснении первого значения, также устроено достаточно сложно по семантике:

1. Высшее сословие, привилегированный слой господствующего класса (обычно родовое дворянство или крупная буржуазия). | | Привилегированная часть какого-л. класса или общественной группы; тот, кто занимает привилегированное положение где-л., в чём-л. Финансовая аристократия. Военная аристократия. Рабочая аристократия (о квалифицированных высокооплачиваемых рабочих) [БТС 2002: 46].

На наш взгляд, более точное толкование слова аристократия приводит словарь Сергея Ивановича Ожегова, Натальи Юрьевны Шведовой „1. Высший родовитый слой дворянства. 2. перен. Привилегированная часть класса или какой-н. общественной группы. Финансовая а, (верхушка финансовых кругов)" [Ожегов, Шведова 2006: 28]. Ожегов, Шведова в номинативном значении выделяют важную сему 'благородство рождения', или 'фактор крови', позволяющий передавать социальный статус по наследству. В этом смысле буржуазия, которую авторы БТС включают в состав аристократии, не обладает этим качеством. Словарь Ожегова, Шведовой во втором значении и БТС в значении собирательного существительного аристократия выделяют своеобразный „демократический" оттенок, позволяющий отвлечься от основания номинации, то есть приписать статус привилегированной части любой группы.

Обращаясь к НКРЯ, здесь и в последующих случаях, мы избрали в качестве единицы поиска не личное существительное, а прилагательное, являющееся его дериватом, позволяющее выявить изменение характера сочетаемости. В атрибутивных словосочетаниях с абстрактными существительными мы намереваемся выявить коннотации и совпадение/несовпадение с переносным значением, описанным словарем. 
НКРЯ обнаруживает контексты, в которых сема высокомерия не актуализируется. Подчеркивается, что аристократизм связан с хорошим воспитанием. Возможно, осознаваемое человеком высокое положение проявляется в чертах его характера, привычках и поведении: аристократический + вежливость, принципы, логика, взгляд на жизнь, холод, совершенство, небрежность, сдержанность, тонкость, небрежение к действительности, праздность, произношение, вкус. В сочетаемости прилагательного выделяются конструкция аристократические манеры:

(3) Однако любопытство и то детская, то аристократическая услужливость, судьба почти всегда - в образе полицейского - неуклонно подводят его к этой роли (Божественный Чарли, „Экран и сцена” 2004.05.06) [НКРЯ];

(4) Точность в слове - самая аристократическая точность, какая только может быть (Елена Тюшина, Владимир Краснов. „Облака” Владимира Краснова, „Новгородские ведомости" 2013) [НКРЯ];

(5) Обаятельный, красивый и изящный молодой человек, блистающий остроумием и одновременно сохраняющий „аристократическую отстранённость”, он быстро стал заметной фигурой в высшем европейском обществе (Наталия Таньшина, Корсиканеи на русской службе, или куда приводит вендетта, „Родина” 2008) [НКРЯ].

Отрицательно маркированным можно признать контекст с существительным презрение:

(6) ...прибыль владельцев фешенебельных ресторанов определялась не столько хорошо разработанной экономической стратегией, сколько некоторым аристократическим презрением к ней (Ирина Волкова. Наш общепит в Париже, „Родина" 2007) [НКРЯ].

В атрибутивных словосочетаниях с прилагательным аристократический присутствует указание на видимый, зрительно воспринимаемый образ объекта. Облик человека покадрово „разбирается” на детали: аристократический нос, аристократическое лицо, аристократические руки, пальцы.

\section{Обыватель}

Возвращаясь к статье энциклопедического словаря, напомним, что личное существительное обыватель обозначает неродовитового жителя города и села [см. Лазаревский 1900]. В Российской империи обывателями не считалась аристократия (дворянство). БТС дает такое толкование этому слову: „1. Постоянный житель какой-л. местности. [...] 2. Неодобр. Человек, лишённый общественного кругозора, с косными, мещанскими 
взглядами, живущий мелкими личными интересами..." [БТС 2002: 694]. Тенденция демократизации проявляется и в этом случае, поскольку слово теряет связь с социальной семантикой. Переносное значение несет отрицательную оценку, которая выражена и в стилистической помете, и в толковании. Заметим, что фигуративное значение слова, являющегося номинацией социального статуса, толкуется через номинацию другого социального статуса мещанский, также приобретшего переносное значение.

Наблюдение над функционированием прилагательного показывает такие коннотации: НКРЯ отражает пренебрежительное отношение говорящего к объекту оценки. В корпусе обнаруживаются контексты (примеры 7, 8), в которых прилагательное обывательский характеризует речь человека, не являющегося специалистом в той или иной предметной области. Такая речь отражает поверхностное представление говорящего о предмете. Характеризация речи отражена в словосочетаниях обывательский + разговоры, рассуждения, суждения, обывательская болтовня, обывательский язык, обывательское злопыхательство, зубоскальство.

(7) Что касается термина „крыша”, он нынче в современном чиновничье-обывательском языке означает покровительство мелким и крупным жуликам, контрабандистам, нечестным торговцам, промышленникам, банкирам, бандитам... (Сергей Есин, Маркиз Астольф де Кюстин. Почта духов, или Россия В 2007 году. Переложение на отечественный Сергея Есина, 2008) [НКРЯ];

(8) Со страниц бесчисленных пособий по „менеджменту” на нас изливается поток лубочных картинок, банальностей, идеологизированного обывательского бреда в знакомом стиле „научного коммунизма” (Сергей Чернышев, Управление собственностью: русский стандарт, „Эксперт" 2004.12.20) [НКРЯ].

Пример 9 свидетельствует о том, что обывательский язык опирается на шаблоны и клише, поэтому затруднен для понимания:

(9) ...я переведу вам то, что прочитала... на свой язык. На язык человека, который переводит обывательские термины с русского на нормальный (Форум: Укрупнение терапевтического участка. В чем подвох?, 2013) [НКРЯ].

Прилагательное обывательский связано с системой взглядов и вполне определенной картиной мира (обывательская точка зрения, кругозор, представления, устои, стереотип), характеризующейся деиндивидуализацией (обывательское быдло). Семы 'непрофессионализма' и 'упрощения' отражаются в словосочетании обывательский уровень.

Прилагательное также становится средством отрицательной оценки, когда говорящий стремится принизить кого-либо (пример 10). Отсюда 
оксюморонное словосочетание обывательская интеллигенция. Противоречие заключается в том, что интеллигенции как социальной группе свойственно не усредненное и упрощенное, а напротив, сложное и индивидуальное, личностное восприятие мира:

(10) ...дурное противоречие между „культурным” Питером и „деревенской” Москвой, укоренившееся в среде обывательской интеллигенции (Иннокентий Шмидт, От заката до расивета - только мысль (2007), „Родина” 2011) [НКРЯ].

Прилагательное обывательский, с одной стороны, предполагает целостную, несамостоятельную картину мира, выражающуюся в системе представлений и в речи, а с другой - отказ от индивидуальности, некую обезличенную коллективность. Говоря о внешности человека, следует утвердительно сказать, что прилагательное не предполагает визуального образа. Напротив, данное слово относится к нематериальной сфере жизни.

\section{Плебей}

Значение заимствованного существительного плебей толкуется следующим образом:

1. В Древнем Риме: представитель низшего сословия, лично свободный, но лишённый возможности пользоваться политическими и гражданскими правами и не владеющий общинной землёй (в противоположность патрицию). 2. В Западной Европе в средние века: представитель городской бедноты. 3. Человек недворянского происхождения, выходец из низших сословий (именовавшийся так в дворянских кругах). 4. Разг. О человеке невежественном, с грубыми, вульгарными манерами [БТС 2002: 840].

Словарь Ожегова, Шведовой оценочного значения не приводит. Как видим, в БТС отрицательное оценочное значение поставлено четвертым, прямые значения не сопровождаются пометами.

Словосочетания с прилагательным плебейский описывают черты характера, поведение, привычки человека (пример 11), его вкус (пример 12), однако касаются и интеллектуальной сферы (пример 13). При таких употреблениях плебейский сближается с обывательским:

(11) И добрался бы, да подвела плебейская привычка на дармовщину кусочничать в тех домах, где вел расследование (Леонид Юзефович. Дом свиданий, 2001) [НКРЯ];

(12) Спроектированный и возведенный с плебейской тягой к яркости фасада при полном пренебрежении не то что к комфорту внутри, но даже к разумной функциональности... (Николай Климонтович. Далее - везде, 2001) [НКРЯ]; 
(13) ...теткина правда-матка казалась лучше мрачной плебейской тупости папиной пассии (Дарья Симонова, Половеиякие пляски, 2002) [НКРЯ].

Заметим, что словарь отмечает в переносном значении вульгарные манеры, невоспитанность и скудный объем знаний, но не ослабленные интеллектуальные способности.

Подобно номинациям представителей благородного сословия, слова, называющие низший слой общества, по данным НКРЯ, создают зрительно воспринимаемый образ. Прилагательное плебейский способно описывать портрет человека целостно и в деталях, выделяя признаки низкого рождения (примеры 14, 15):

(14) Смотри, какой низкий лоб, какие плебейские скулы... (Станислав Рассадин. Книга прощаний. Воспоминания о друзьях и не только о них, 2004-2008) [НКРЯ];

(15) Сухой повел широкими плебейскими ноздрями, точно племенной бык... (Вадим Громов, Компромат для олигарха, 2000) [НКРЯ].

Русский синоним плова плебс - существительное чернь - ведет себя совершенно иначе в словообразовательном аспекте: не образует прилагательного и личного существительного. Чернь также многозначное слово и употребляется в современной речи:

1. Книжн. = Чернота (1-2 зн.)... 2. Художественная обработка металла, при которой гравированный на нём рисунок заполняется чёрным матовым сплавом из серебра, меди, серы и т.п.; самый этот сплав... 3. Гравировка, декоративная отделка, выполненная таким способом... 4. Спец. Чёрная угольная краска органического происхождения... 5. Устар. Простой народ, чёрный люд, низы общества... 6. Книжн. О рядовых представителях какой-л. среды; о духовно ограниченной, чуждой высоких помыслов среде, толпе... 7. Спец. Чернолесье; густой непроходимый лес, дебри [БТС 2002: 1475].

К социальной стратификации имеют отношение пятое и шестое значения существительного. И в этом случае при образовании переносного значения проявляется признак своеобразной демократизации, когда перестает быть актуальной общественная иерархия. Указание на отрицательную оценку - в толковании переносного значения, в частности, в словосочетании духовно ограниченный. У прилагательного черный БТС отмечает в качестве четвертого значения с пометой устаревшее „принадлежащий к низшим непривилегированным сословиям, к простонародью" [БТС 2002: 1474]. Однако в современной речи в этом значении слово черный встречается нечасто.

На наш взгляд, препятствием к активному употреблению в речи существительного в переносном значении является принадлежность его к книжной речи, что лишает его употребление экспрессивности. 
Пример 16 позволяет интерпретировать слово чернь в переносном значении, когда говорящий имеет в виду безынициативность людей. В примере 17 показателем переносного значения существительного становится определение либеральный:

(16) Ненависть нищей черни к тем, кто чего-то в жизни хочет и добился (Николай Дежнев, Принции неопределенности, 2009) [НКРЯ];

(17) Тогда власть имея от народа мандат на созидательные реформы, сыграла в поддавки с либеральной чернью (Владимир Попов, Вся Россия - Сибирь? (Мобилизационная модель - вместо „окрошки” из Фридмана, Столыпина и Дэн Сяопина), „Завтра” 2003.07.10 [НКРЯ].

Итак, подведем итоги. Деактуализация прямого номинативного приводит к возникновению характеризующего значения. На это указывает переносное значение слова сословие, когда становится произвольным признак, на основании которого люди объединяются в группы. Мы проанализировали употребление в речи прилагательных, являющихся дериватами номинаций социальных статусов, которые находятся на верхних, в середине и на низших ступенях социальной лестницы. Все переносные значения отрицательно маркированы. Семантическая амбивалентность наблюдается лишь у слова аристократический, поскольку сема 'высокомерия' не проявляется регулярно во всех контекстах; чаще с помощью данного прилагательного описываются эстетически утонченные объекты. НКРЯ позволяет обнаружить у данного прилагательного семы 'породистости'. У слова обывательский, отсылающего к середине социальной лестницы, словарь отмечает отсутствие общественного кругозора, в употреблении же проявляется сема 'поверхностности', 'непрофессионализма'. Наконец, прилагательное плебейский, у которого словарь отмечает в семантике 'невежество', 'грубость' и 'отсутствие хороших манер', в употреблении эксплицируется семантика интеллектуальной ограниченности. Сходство с употреблением в речи слова аристократический проявляется в том, что плебейский способно описывать внешность человека, в котором наблюдатель подозревает низкое происхождение. Заметим, что подобной перцептивности лишено прилагательное обывательский. Семантически близкое к существительному плебс слово чернъ, в прямом значении отсылающее к социальным низам, не образует адъективного деривата и личного существительного. Причины ограниченного употребления слова чернъ в речи мы видим в стилистической окраске производящего существительного. 


\section{Библиография}

Арутюнова Н. Д. 1978. Функииональные типы языковой метафоры, „Известия Академии наук СССР”. Серия литературы и языка, т. 37, № 4, с. 333-343.

Арутюнова Н. Д. 1990. Метафора и дискурс, [в:] Арутюнова Н. Д. (сост.), Теория метафоры, Москва: Прогресс, с. 5-32.

Балашова Л. В. 2014. Русская метафорическая система в развитии XI-XXI вb., Москва: Рукописные памятники Древней Руси: Знак.

Баранов А. Н. 2014. Дескриптивная теория метафоры, Москва: Языки славянской культуры.

Лазаревский Н. 1900, Сословия, [в:] И. Е. Андрееский, К. К. Арсеньев, Ф. Ф. Петрушевский (ред.), Энциклопедический словарь (в 86-х томах), т. 60, Санкт-Петербург: Издательское дело, Брокгауз и Ефрон, электронный ресурс: http:/ /www.vehi.net/ brokgauz/ (доступ: 11.11.2018).

Лакофф Дж., Джонсон М. 2004. Метафоры, которыми мы живем, Москва: Едиториал УРСС.

Ожегов С. И., Шведова Н. Ю. 2006. Толковый словарь русского языка, Москва: Темп.

Радаев В. В., Шкаратан О. И. 1996. Социальная стратификация, Москва: Аспект Пресс.

Сушкова-Ирина Я. И. 2010. Динамика соииальной стратификации и ее представленность в картинах мира, „Знание. Понимание. Умение”, № 4, электронный ресурс: http:/ / www.zpu-journal.ru/e-zpu/2010/4/Sushkova-Irina/ (доступ: 11.11.2018).

Телия В. Н. (ред.) 1988. Метафора в языке и тексте, Москва: Наука.

\section{Список используемых сокращений}

БТС - Кузнецов С. А. (ред.) 2002. Большой толковый словарь русского языка, Санкт-Петербург: Норинт.

НКРЯ - Национальный корпус русского языка, электронный ресурс: http://ruscorpora. $\mathrm{ru} /$ search-main.html

САР - Словарь Академии Российской, по азбучному порядку расположенный. 1806-1822. Издание 2-е, Санкт-Петербург. 